\title{
Assessing the Seismic Hazards of Afghanistan
}

$\mathrm{F}$ Tollowing decades of strife and hardship, Afghanistan is recovering and rebuilding. Reconstruction of the country's infrastructure and development of its natural resources are progressing but are jeopardized by the omnipresent threat of strong, damaging earthquakes to much of the country (fig. 1). Afghanistan is located in a tectonically active region where earthquakes have historically caused damage, not only from strong ground shaking and surface rupture, but also from liquefaction and extensive landsliding.

To accurately assess the seismic hazards of Afghanistan, the U.S. Geological Survey (USGS) is using a multiphase strategy to collect data and relevant information. The USGS will analyze these data and utilize this information to develop a suite of probabilistic national seismic hazard maps. These maps will provide the Afghan Government and the international community with scientifically based forecasts about the level of seismic hazard in various parts of the country, ensuring that the country's reconstructed infrastructure is both durable and resistant to earthquake catastrophies. Additionally, the hazard maps will allow the design and construction of each structure to be tailored to the local hazard level, thereby optimizing the balance of safety and cost.

The USGS seismic-hazard assessment involves at least six elements:

1. Compile regional catalogs of historical and instrumental earthquakes and prepare maps

2. Develop a seismotectonic map

3. Conduct studies of earthquake source zones and develop a Quaternary fault map

4. Provide training for Afghan scientists and technicians

5. Establish a regional network of seismographs to monitor earthquakes

6. Develop a regional seismic hazard map

\section{Regional catalog of historical and instrumental earthquakes}

A comprehensive master catalog of historical and instrumental earthquakes in the region is a fundamental first step in assessing the seismic hazard. This catalog will merge records of significant historical earthquakes that span many centuries with the more recent instrumentally located earthquakes. Although the more recent earthquakes will have more accurate locations and magnitudes, a catalog of large historical earthquakes that spans many centuries is a valuable resource for hazard analysis. The catalog will be used to generate seismicity maps and is essential input for determining the seismotectonic framework as well as the seismic hazard.

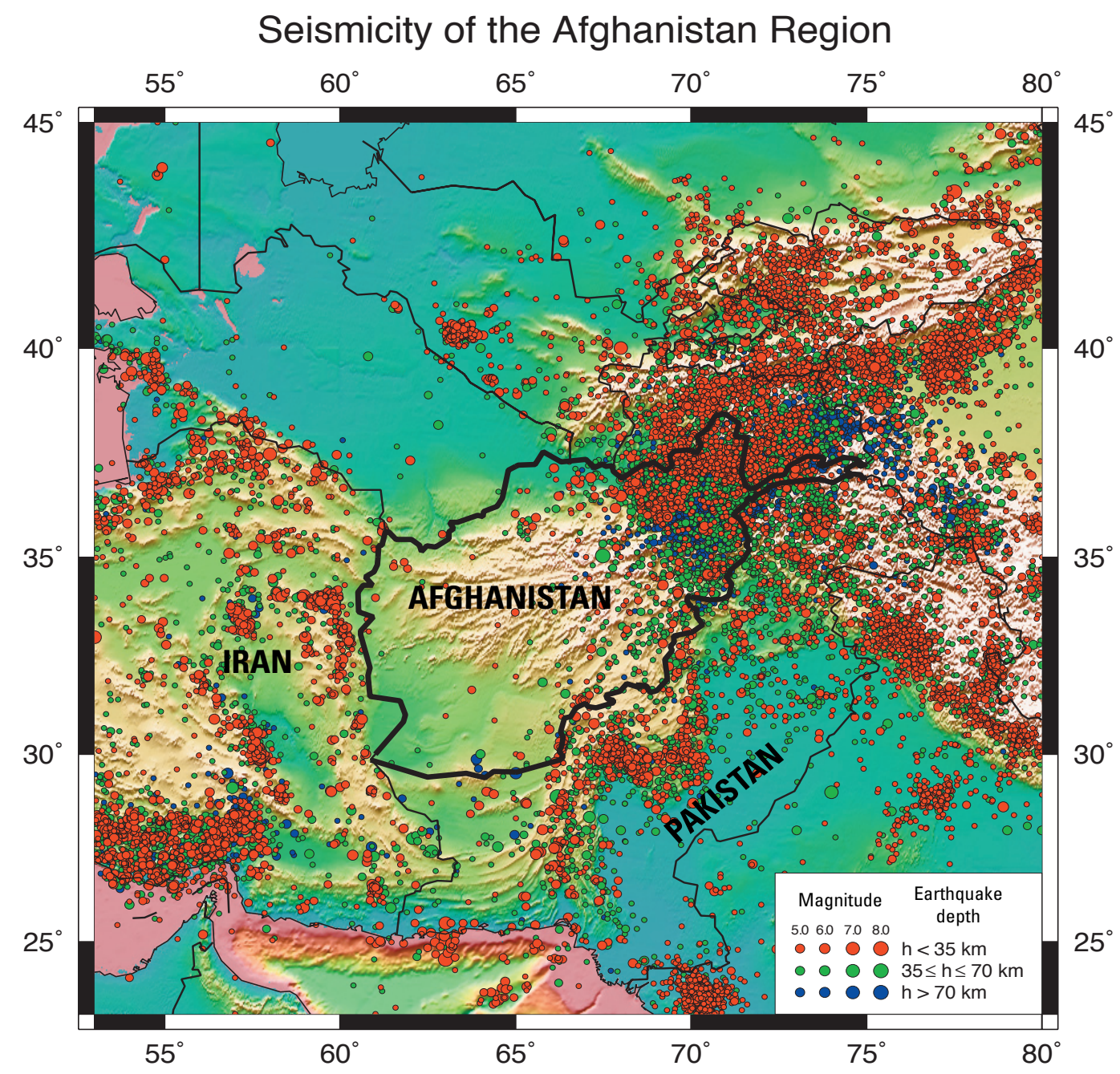

Figure 1. Preliminary instrumental seismicity of the Afghanistan region. Locations and magnitudes for earthquakes from 1900 through 1963 are from the "Centennial Catalog" of Engdahl and Villasenor (2002, International Handbook of Earthquake and Engineering Seismology, Academic Press, p. 665-690). Locations and magnitudes for earthquakes from 1964 through 2004 are from the current version of the global earthquake catalog calculated with the methodology of Engdahl, van der Hilst, and Buland (1998, Bulletin of the Seismological Society of America, v. 88, p. 722-743). h, depth in kilometers. 


\section{Seismotectonic map of Afghanistan}

A seismotectonic map showing information about geologically young (Quaternary) faulting is needed to conduct a seismic hazard analysis and to create hazard maps (fig. 2). A typical seismotectonic map shows earthquakes, young faults, stress orientations, tectonic setting, and other relevant information. Seismotectonic data for Afghanistan come from existing earthquake catalogs, paleoseismic studies, geologic maps and reports, and from insights developed while compiling this information.

The seismotectonic map of Afghanistan provides a structural and tectonic framework for interpreting the distribution of earthquakes and surface-rupturing faults in the country. The seismotectonic map is a tool for hazard analysts and is also useful to other earth scientists who seek an overview of the likely sources of earthquakes.

\section{Earthquake source zones and the Quaternary fault map}

Seismic source zones are active geological structures that generate earthquakes. The objective of studying them is to understand the timing and extent of large-magnitude $(M>6.5)$ prehistoric earthquakes. Many structures that generate large earthquakes are expressed at the ground surface, commonly as faults or folds. Detailed studies of these features provide crucial information about the long-term rates of movement, the amount of slip during individual earthquakes, and the times of past movements. Information on prehistoric earthquakes (which is termed paleoseismology) helps supplement the catalogs of historical and instrumental earthquakes. For example, faults that have repeat times of hundreds to thousands of years for largemagnitude earthquakes may not have ruptured in the relatively short historical record. By extending the seismic record back thousands of years we get a more complete picture of the potentially damaging geological structures in the country.

\section{Proposed technical training}

A key goal of USGS activities in Afghanistan is to foster the development of in-country expertise in seismic monitoring and hazard assessment. As part of this program, the USGS will provide hands-on training for Afghan geophysicists, geologists, and technicians in the installation and maintenance of seismic networks, geological investigations of active faults, and the collection and analysis of seismological data.

\section{Proposed seismic and deformation monitoring in Afghanistan}

Earthquakes and the damaging ground motion that they generate are the direct result of movement on faults, and these movements are caused by forces that originate deep within the Earth. To accurately assess the hazard posed by earthquakes, it is essential to understand the style and rate of deformation in the Earth's crust. Earthquakes release strain that accumulates as a result of the ongoing deformation, so identifying the areas and rates of strain accumulation yields a first-order evaluation of seismic hazard.

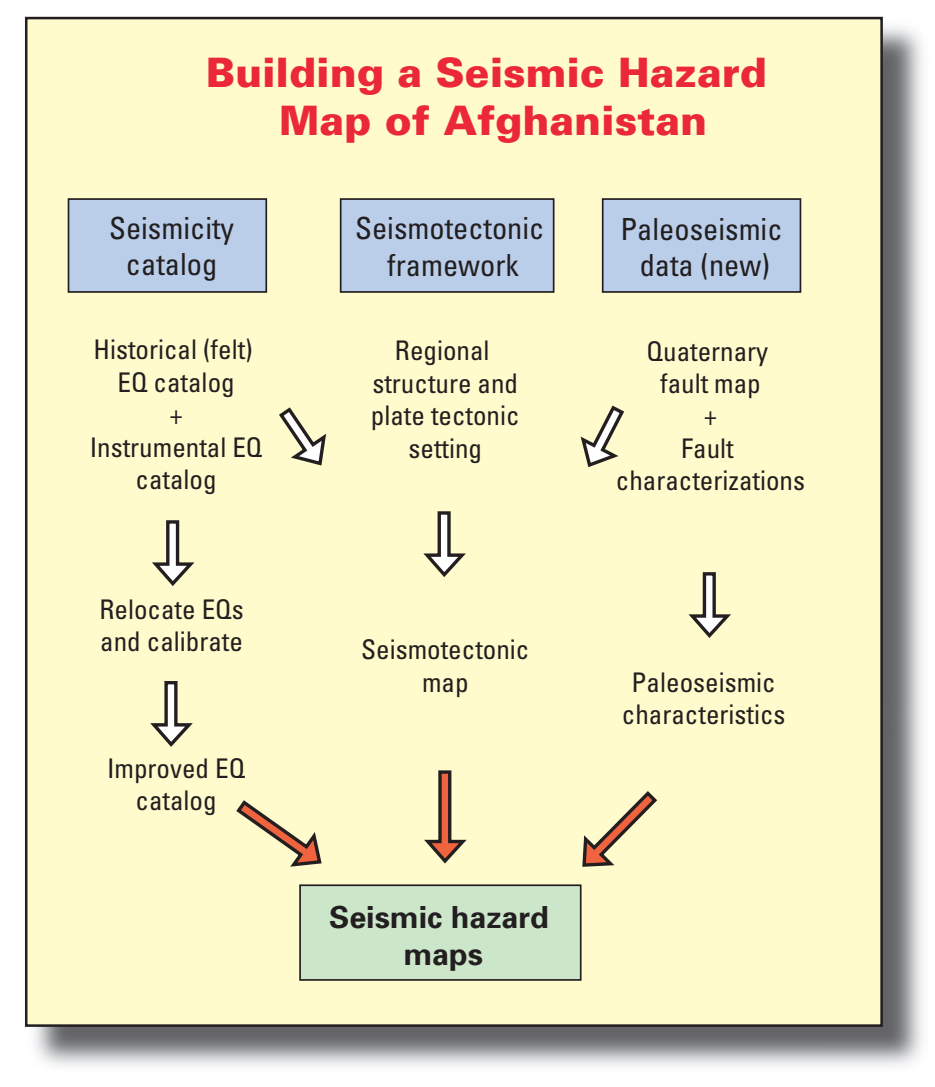

Figure 2. Generalized diagram showing sources of information (indicated in blue) and interim steps needed to develop seismic hazard maps. EQ, earthquake.

Figure 3 shows the distribution of proposed collocated seismic and Global Positioning System (GPS) stations (blue stars) and supplementary GPS stations (yellow stars) that are needed to develop a basic understanding of the earthquake potential and hazards for Afghanistan. Seven collocated seismic and GPS stations are distributed across the country in order to adequately monitor the seismically active northeastern part of the country, as well as areas near the Afghan-Iran and Afghan-Pakistan borders where earthquakes can potentially cause extensive damage. By collocating seismographs and continuous real-time GPS systems at these sites, we can map the broad deformation field across major tectonic boundaries and selected active faults.

The yellow stars in figure 3 show locations of proposed semipermanent GPS stations that can be deployed for varying lengths of time to provide high-resolution deformation rates on the active fault systems in northeastern Afghanistan. These stations could be placed at independent sites where they can continuously collect data for as long as 1 year. These data can be used to determine local deformation rates and to define the interactions among fault systems. At the present time, regional deformation rates, which are most accurately obtained from GPS data, are poorly known for much of central Asia and Afghanistan. In the most seismically active parts of Afghanistan, there are no direct measurements of crustal deformation. Modern GPS and seismic networks can answer crucial questions about the total rate and local variations of crustal deformation and associated seismicity throughout Afghanistan, which is vital to assessing earthquake hazards and identifying active faults. 


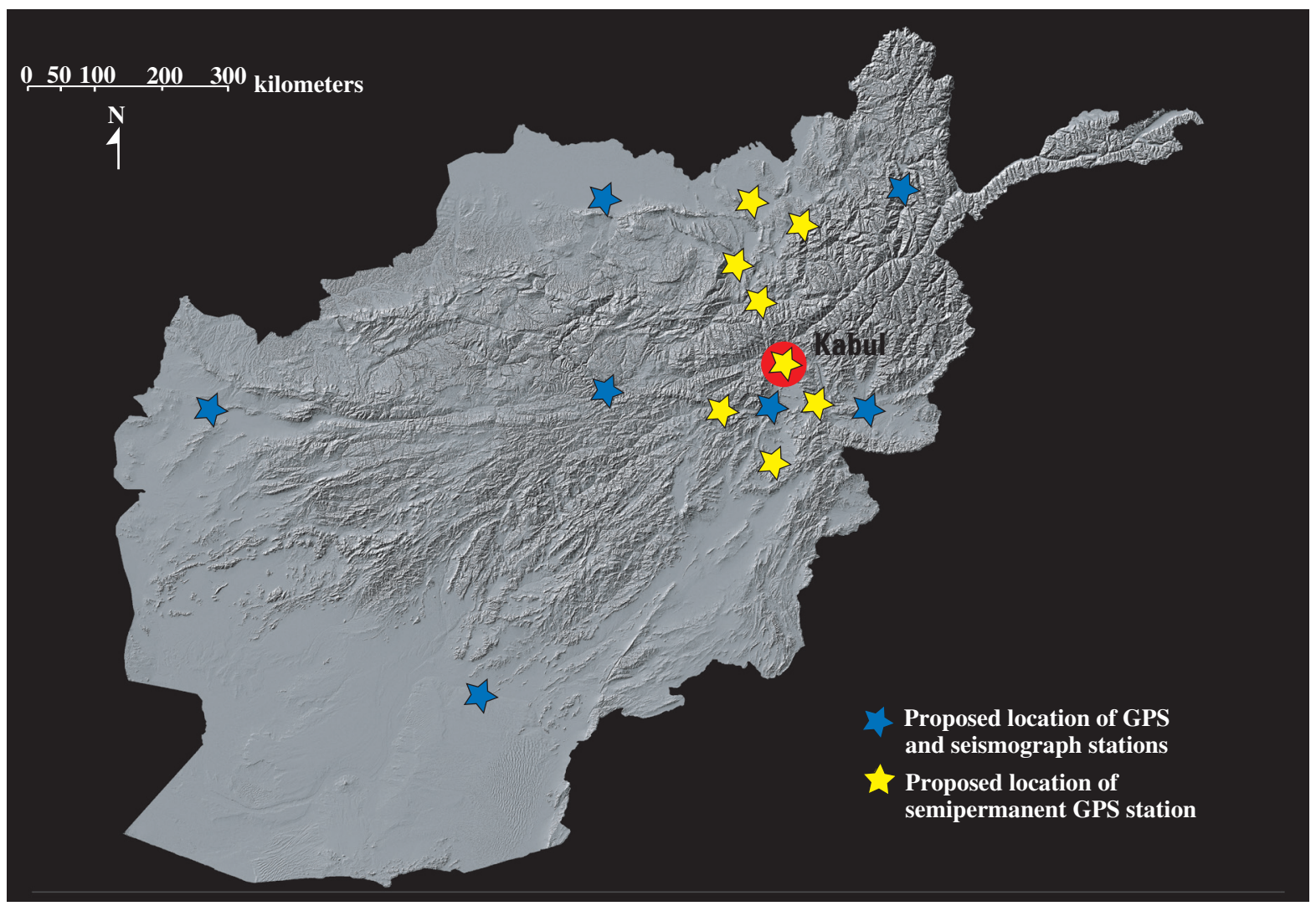

Figure 3. Shuttle radar topographic map of Afghanistan showing locations of proposed GPS and seismograph stations. Map credit: Peter G. Cherico, USGS.

\section{Seismic hazard maps}

By determining the locations and frequency of earthquakes, the seismotectonic setting, and fault rupture times and patterns, we can make scientific forecasts and create maps that show the probable amount of ground motion (during shaking) for both specific localities (such as Kabul) and for larger regions, such as the entire country. Figure 4 shows a generalized hazard map for the United States. The contours, from low to high hazard, are based on the percent $g$ (acceleration due to the force of gravity) during ground shaking. The map closely follows the distribution of modern seismicity, but active faults have a profound effect in areas of low to moderate historical seismicity, such as the Western United States. Such maps of Afghanistan will allow the government and private sector to make informed decisions about the design and placement of critical structures, such as hospitals, dams, pipelines, and other essential elements of the country's infrastructure.

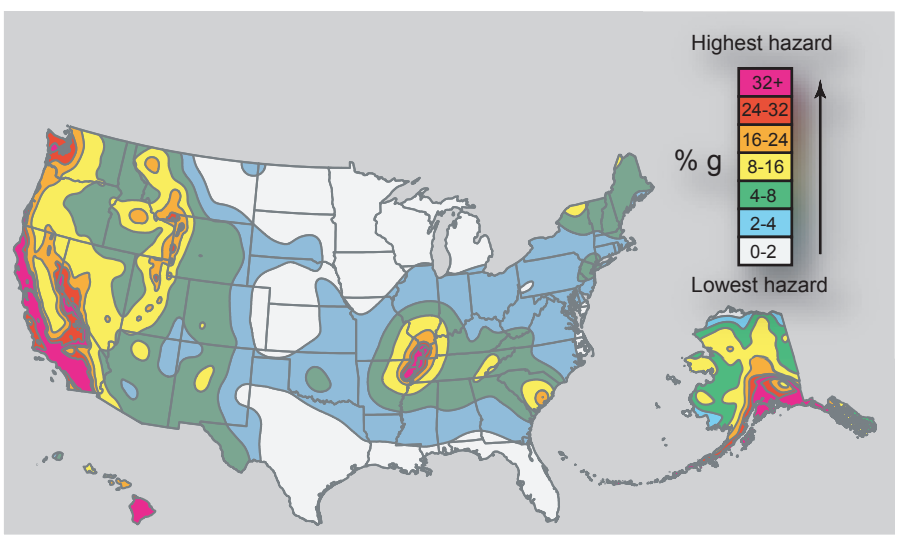

Harley Benz, Michael Machette, Stuart Sipkin and Russell Wheeler

\section{For more information, contact:}

\section{U.S. Geological Survey}

Geologic Hazard Team

MS 966, P.O. Box 25046

Denver, Colorado 80225-0046

http://geohazards.cr.usgs.gov/

Earthquake catalog: Stuart Sipkin, sipkin@usgs.gov, 303-273-8415

Seismotectonics: Russell Wheeler, wheeler@usgs.gov, 303-273-8589

Quaternary faults: Michael Machette, machette@usgs.gov, 303-273-8612

Seismic networks: Harley Benz, benz@usgs.gov, 303-273-8497

Project coordinator: Anthony Crone, crone@usgs.gov 303-273-8591

\section{Design and layout: Margo Johnson}

Figure 4. Simplified seismic hazard map for the United States. 